\title{
Monocyte Toll-Like Receptor 4 Expression and LPS-Induced Cytokine Production Increase during Gestational Aging
}

\author{
ELISABETH FÖRSTER-WALDL, KAMBIS SADEGHI, DIETMAR TAMANDL, \\ BERNADETTE GERHOLD, ULRIKE HALLWIRTH, KLAUDIA ROHRMEISTER, MICHAEL HAYDE, \\ ANDREA R. PRUSA, KURT HERKNER, GEORGE BOLTZ-NITULESCU, ARNOLD POLLAK, AND \\ ANDREAS SPITTLER \\ Department of Pediatrics and Juvenile Medicine [E.F.-W., B.G., K.R., M.H., A.R.P., K.H., A.P.], \\ Department of Surgery [K.S., D.T., U.H., A.S.], Department of Pathophysiology [G.B.-N.], Medical \\ University of Vienna, 1090 Vienna, Austria, Ludwig Boltzmann Institute for Pediatric Endocrinology and \\ Immunology [K.H.], 1090 Vienna, Austria
}

\begin{abstract}
Premature newborns are highly susceptible to severe bacterial infections. This is partially due to their immature innate immune system, characterized by decreased neutrophil and monocyte activity as well as by reduced concentrations of complement factors. However, additional mechanisms might be important for innate immunity and are still the subject of considerable debate. The importance of pattern recognition domains such as Toll-like receptors (TLR) has been fully acknowledged within the last few years. Therefore, we investigated age-related monocyte TLR4 expression and lipopolysaccharide-induced cytokine secretion from very low birth weight infants (VLBWI) and from newborns after wk 30 of gestation in comparison to healthy adults. In VLBWI, expression of TLR4 surface protein, detected by flow cytometry, and TLR4-specific mRNA, quantified by real timePCR, were significantly reduced in comparison to mature infants and to adults. Reduced TLR4 expression was paralleled by
\end{abstract}

\section{ABSTRACT}

significantly diminished ex vivo LPS stimulated IL- $1 \beta$, IL-6, and tumor necrosis factor- $\alpha$ secretion into whole blood. We conclude that, in VLBWI, the minimized expression of TLR4 contributes to the susceptibility of VLBWI to infections with Gram-negative bacteria due to the lack of cytokines to boost initial immune response. (Pediatr Res 58: 121-124, 2005)

CB, cord blood

Abbreviations

LPS, lipopolysaccharide

PAMP, pathogen-associated molecular pattern

PB, peripheral blood

PBMC, peripheral blood mononuclear cells

TLR, Toll-like receptor

TNF, tumor necrosis factor

VLBWI, very low birth weight infants
Bacterial infections are a major cause of neonatal morbidity $(1,2)$, and premature newborns are highly susceptible to infections (3). This increased susceptibility appears to be related to immaturity of the immune system. Maturation of the immune system includes specific humoral and cellular responses as well as nonspecific innate immune mechanisms, such as factors of the complement system and phagocyte activity (3-5).

Monocytes and macrophages play a central role in both specific and nonspecific immunity against bacterial, viral, and fungal infection. In VLBWI, a substantial decrease of fully

Received July 12, 2004; accepted October 18, 2004.

Correspondence: Andreas Spittler, M.D., Surgical Research Laboratories, AKH, 8G 9.13, Medical University of Vienna, Waehringer Guertel 18-20, 1090 Vienna, Austria; e-mail: andreas.spittler@meduniwien.ac.at

Supported in part by the "Hygiene Fonds" of the Medical Faculty at the University of Vienna, Austria. E.F.-W. was supported by the Charlotte Bühler Fellowship H176-B08 of the Austrian Science Fund.

DOI: 10.1203/01.PDR.0000163397.53466.0F functional phagocytes has recently been reported (6). The Toll protein has been identified as a receptor controlling dorsoventral polarization during embryonic development of Drosophila larvae and serves a defensive function (7). Structures homologous to Toll receptors were found in mammalian cells $(8,9)$ and termed TLR. Within the last few years, 10 human TLR have been described and characterized as important sensors of the innate immune system $(9,10)$. These TLR are phylogenetically conserved and are involved in recognition of microbial PAMP. TLR4 functions as the transmembrane component of the LPS receptor. In addition to LPS, the major glycolipid component of the outer membrane of Gram-negative bacteria, TLR4 recognizes saturated and unsaturated fatty acids such as lipoteichoic acids from Gram-positive bacteria, and heat-shock proteins $(8-10)$. Binding of these ligands to TLR4 triggers an intracellular signalling cascade sharing features with so-called Toll/IL-1 receptor (TIR) signalling, ultimately leading to nu- 
clear translocation of nuclear factor (NF)- $\kappa$ B. This cascade results in transcriptional activation of genes encoding proinflammatory mediators such as TNF- $\alpha$, IL- $1 \beta$ and IL-6, chemokines, and colony stimulating factors. All these secreted proteins are important in boosting primary immune defense. They create the systemic and local inflammatory response to infection (11).

Despite the fact that TLR have been investigated with increasing interest during recent years, little is known about the maturation of TLR during fetal development and about the possible involvement of TLR immaturity in immunologic deficiencies of the newborn. In mice, one recent study provides evidence that TLR4 mRNA levels in the immature fetal lung are decreased in comparison to mature newborns, and that these levels increase further after birth (12).

We hypothesized that TLR4 expression and TLR-related cytokine secretion are dependent on gestational aging in humans as well. More insight into these important mechanisms might have implications for diagnostic procedures in neonatal sepsis and might provide therapeutic options in impending preterm delivery.

\section{METHODS}

Sample selection. Cord blood samples were collected from spontaneous deliveries and cesarean sections, respectively. Spontaneous term deliveries with neither a history of infection during pregnancy nor clinical signs of infection at delivery were not evaluated further. Preterm deliveries by cesarean section were checked for infection by laboratory diagnosis (white blood cells, CRP, IL-8) and by placenta histology (amnionitis). Because elevated CRP and/or IL-8 were determined as exclusion criteria, the plasma of the samples obtained showed neither pathologic CRP nor IL-8 increases.

Blood samples. CB was obtained by puncture of the umbilical cord from the placental side immediately after transsection of the umbilical cord. The samples were collected in heparinized syringes and processed within $2 \mathrm{~h}$ of collection. The study was approved by the local ethics committee and informed consent was obtained.

Peripheral venous blood (PB) was drawn from healthy adult volunteers. Heparinized whole blood from $\mathrm{CB}$ or $\mathrm{PB}$ was diluted 1:1 in endotoxin-free Hank's balanced salt solution (HBSS; BioWhittaker, Verviers, Belgium), without $\mathrm{Ca}^{2+}$ and $\mathrm{Mg}^{2+}$. PBMC were isolated by Ficoll gradient (Ficoll-Paque PLUS, Amersham Biosciences, Little Chalfont, Buckinghamshire, UK) centrifugation. PBMC $\left(5 \times 10^{6}\right)$ were washed three times with cold endotoxinfree HBSS without $\mathrm{Ca}^{2+}$ and $\mathrm{Mg}^{2+}$ and immediately lysed in $1 \mathrm{~mL}$ Trizol reagent (Invitrogen, Carlsbad, CA).

Immunofluorescence staining. Surface staining of TLR4 was performed in $50 \mu \mathrm{L}$ whole blood with an anti-human TLR4 MAb (MAb, PE labelled, clone HTA125, eBioscience, San Diego, CA). To detect monocytes, cells were additionally stained with anti-CD14 MAb (FITC, My4, Beckman Coulter, Inc., Fullerton, CA). Control cells were stained with an isotype antibody (MOPC173, mouse IgG2a, eBioscience). Cells were incubated on ice for $30 \mathrm{~min}$. Subsequently, red blood cells were lysed and washed three times with HBSS. The expression of TLR4 on $\mathrm{CD} 14^{+}$gated monocytes was measured by flow cytometry (EPIXS-XL MCL, Beckman Coulter, Inc.). Routinely, $2.5 \times 10^{3}$ CD $14^{+}$cells were counted (13).

RNA isolation and real-time PCR. Total RNA was isolated from PBMC using Trizol reagent as specified by the manufacturer. Purity and quantity of the extract were determined by photometry. All reagents and devices used for real-time PCR were obtained from Applied Biosystems (Foster City, CA). For reverse transcriptase reaction, a total of 200 ng RNA was reverse transcribed to cDNA using TAQ-Man reverse transcription agents (Applied Biosystems). Resulting cDNA was stored at $-20^{\circ} \mathrm{C}$ until amplification.

Quantitative real-time PCR was conducted for TLR4 and 18S ribosomal RNA as internal control. TLR4 and 18S rRNA primer and probes were obtained from Applied Biosystems (Assay by Design). Primers for TLR4 were: 5'-CAG AGT TTC CTG CAA TGG ATC A-3'; 3'-TGC TTA TCT GAA GGT GTT GCA CAT-5' and 5'-AGG CAG CTC TTG GTG GAA GTT GAA CGA AT-3' for the fluorescence-labeled TAQ-Man probe (FAM as a reporter dye and TAMRA as a quencher). All experiments were performed in triplicate in 96-well plates using TAQ-Man Universal Master Mix. Real-time PCR amplification was performed on a Gene Amp 5700 Sequence Detection System. PCR conditions were $50^{\circ} \mathrm{C}$ for $2 \mathrm{~min}, 95^{\circ} \mathrm{C}$ for $10 \mathrm{~min}$, then 45 cycles at $95^{\circ} \mathrm{C}$ for $15 \mathrm{~s}$, and $60^{\circ} \mathrm{C}$ for $1 \mathrm{~min}$.

For quantitative evaluation of gene expression, TLR4 mRNA levels were normalized to the 18S-mRNA as suggested by Applied Biosystems (User Bulletin \#2, December 11, 1997).

LPS stimulation. One hundred microliters of cells were stimulated with 1 $\mu \mathrm{g} / \mathrm{mL}$ LPS (100 $\mu \mathrm{L} \mathrm{CB}$ or PB diluted in $900 \mu \mathrm{L}$ RPMI 1640 medium) at $37^{\circ} \mathrm{C}$ in a $5 \% \mathrm{CO}_{2}$ air atmosphere. LPS [serotype R515 (Re) (liquid), Alexis Biochemicals, Vienna, Austria] exclusively stimulates TLR4 as shown with macrophages from TLR4 wild-type compared with TLR4 deficient mice (Product data sheet ALX-581-007, Alexis Biochemicals). After $4 \mathrm{~h}$ of stimulation, cell culture supernatants were collected and frozen immediately at $-70^{\circ} \mathrm{C}$ until further use. For control experiments, cells were cultured under equal culture conditions without LPS (13).

Cytokine ELISA. Frozen aliquots of cell culture supernatants were thawed immediately before analysis. The concentration of cytokines (IL- $1 \beta$, IL-6, TNF- $\alpha$ ) was measured with commercially available ELISA kits (Amersham Biosciences). Cut-off values for IL- $1 \beta$ and IL-6 were $10-400 \mathrm{pg} / \mathrm{mL}$ with a sensitivity of $<1 \mathrm{pg} / \mathrm{mL}$, and for TNF- $\alpha 25-1,000 \mathrm{pg} / \mathrm{mL}$ with a sensitivity of $<5 \mathrm{pg} / \mathrm{mL}$. Duplicate measurements were performed for each sample. The OD of samples in comparison to a provided standard was measured in an ELISA plate reader (Dynatech Labs, Chantilly, VA).

Statistics. Data are presented as mean \pm SD. Statistical analysis was performed using the SPSS software package (SPSS for Windows, Release 8.0.0, Chicago, IL). A probability of $p<0.05$ was considered statistically significant. Groups were compared by $t$ test.

\section{RESULTS}

Decreased surface expression of TLR4 on monocytes from preterm infants. Monocytes were identified by immunofluorescence using anti-CD14 MAb. As shown in Figure 1, premature newborns $(n=6)$ have significantly lower expression of TLR4 surface protein $(p<0.01)$ than newborns of later gestational age $(n=11)$. Moreover, the expression of TLR 4 on monocytes from adult healthy donors $(n=10)$ is significantly higher than in newborns $(p<0.01)$. There was no correlation between CD14 expression and TLR4 expression between groups of newborns. A significantly higher expression of CD14 surface antigen was found in monocytes from adults. However, we found neither a correlation between TLR4 expression and CD14 expression nor between CD14 ${ }^{-} /$TLR $^{+}$cells in cord blood (data not shown).

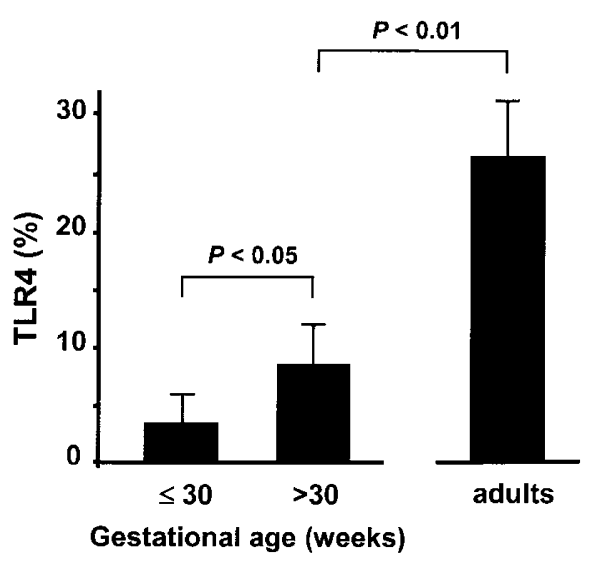

Figure 1. Expression of TLR4 on CD14-positive monocytes is significantly reduced $(p<0.05)$ in very early preterm infants $(n=6)$ compared with cells from newborns from later gestational ages $(n=11)$. Furthermore, monocyte TLR4 expression in adults $(n=10)$ is significantly higher $(p<0.01)$ than in newborns. 
Lower mRNA expression of TLR4 in cells from preterm newborns. Our data of decreased surface expression of TLR4 on monocytes from different age groups correspond to the results obtained from mRNA expression of these TLR. As shown in Figure 2, a statistically significant difference in TLR4 mRNA expression was found between cells from very early preterm infants (gestational age $<30 \mathrm{wk}, n=6$ ) and newborns from later gestational ages $(>30, n=8)$. Furthermore, a significant reduction in the amount of TLR4-specific mRNA in monocytes from newborns in comparison to levels in monocytes from adult donors $(n=10)$ was found $(p<0.05)$.

Reduced cytokine production after LPS stimulation in preterm newborns. The functional outcome of stimulating TLR4 on monocytes, which is achieved by LPS stimulation, is the production of IL- $1 \beta$, IL- 6 , and TNF- $\alpha$ cytokines. The production of these cytokines is strikingly reduced in the samples from very early preterm infants $(n=20)$, in comparison to cytokine production in later stage newborns $(n=20)$, and in adults $(n=10)$. The stimulation of monocytes from adults with LPS induced a 2- to 3-fold increase in the concentrations of these cytokines in comparison to newborns (Fig. 3).

\section{DISCUSSION}

Newborns, particularly premature VLBWI, are far more susceptible to bacterial infections than adults. One explanation for the greater risk of sepsis in premature low birth weight infants (3) in the neonatal intensive care unit is that premature infants are frequently exposed to invasive procedures such as umbilical and intravascular catheterization, intubation, and assisted ventilation. Contamination and colonization of these catheters and tubes with microbes is widely known to be a potent source of nosocomial infections (14-16).

A second explanation is that premature infants have an immature immune system, which plays a major role in infectious morbidity and mortality. Monocytes/macrophages as well as the dendritic cells that belong to the mononuclear phagocytic system are important effector cells of the innate immune response against microbial antigens, which in turn leads to activation of the adaptive immune system $(17,18)$. Circulating

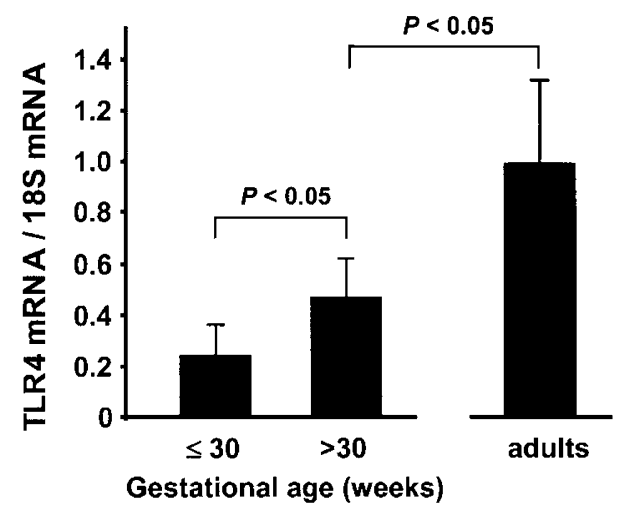

Figure 2. Specific TLR4 mRNA amounts in mononuclear cells from very early preterm infants $(n=6)$ are significantly lower $(p<0.05)$ than in cells from newborns from later gestational ages $(n=8)$. A significant reduction $(p$ $<0.05$ ) of TLR4 mRNA appears in cells from all newborns in comparison to levels in cells from adults $(n=10)$. Each value represents mean \pm SD.
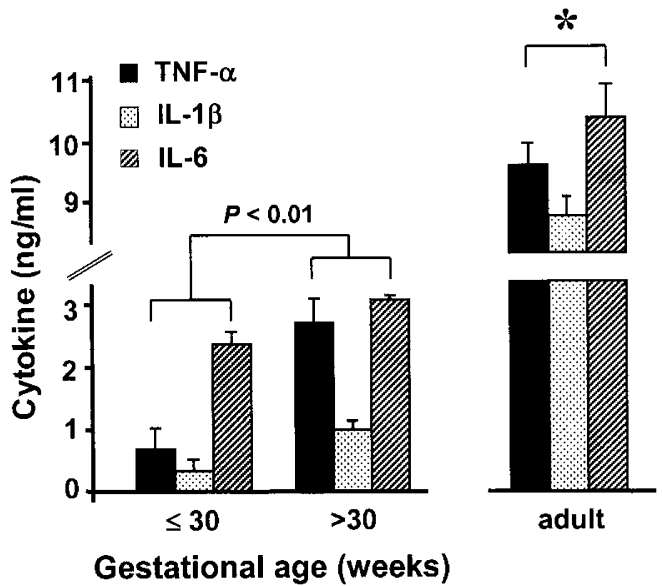

Figure 3. Cytokine production in whole blood after LPS stimulation at different gestational ages. Production of IL- $1 \beta$, TNF- $\alpha$, and IL- 6 was significantly reduced $(p<0.01)$ in very early preterm infants $(n=20)$, in comparison to cytokine production in later stage newborns $(n=20)$. LPSstimulation of cells from adults $(n=10)$ induced 2- to 3 -fold cytokine levels $(* p<0.001)$ in comparison to newborns.

monocytes do not appear before wk 20 of gestation. Monocytes from preterm newborns are functionally deficient (19). We found decreased HLA-DR expression on monocytes from preterm neonates (20). Recently, we have demonstrated that monocytes from VLBWI display decreased phagocyte activity in newborns developing septic complications (6). It has also been shown that the expression of the CD14 antigen on mature monocytes, a cell surface receptor involved in the response to LPS, is dependent on gestational maturation (19). In our study we could not detect significant differences in CD14 expression between children $\leq 30$ wk and $>30$ wk of gestational age. However, significantly higher expression was detectable in adults. Thus, monocytes in premature VLBWI can be considered phenotypically and functionally immature $(20,21)$.

TLR4 is essential for microbial recognition of Gramnegative bacterial compounds and the initiation of the innate immune response $(10,11)$. In the present study, we reveal the possible implication of TLR4 expression and function for immunologic immaturity and vulnerability of premature and even mature newborns. Our data demonstrate reduced expression and decreased functionality of TLR4 in preterm infants, and thus strongly support the essential role of TLR4 in their increased susceptibility to infection. This finding is underlined by several studies associating mutations in the TLR4 gene with higher risk for bacterial infections and deficient responsiveness to LPS (22-24). Binding of LPS to the TLR4/CD14 and MD-2 protein triggers activation of the NF- $\kappa \mathrm{B}$ pathway, through the adaptor molecule MyD88, kinases, and other signalling and regulatory molecules, ultimately leading to production of cytokines, chemokines, and colony stimulating factors (25). Proinflammatory cytokines, such as TNF- $\alpha$, IL- $1 \beta$, and IL-6, are produced by activated monocytes and Th1 lymphocytes, and have a crucial role in the induction of immune response, and in clearance of pathogens. The production of pro-inflammatory and antiinflammatory cytokines may correlate with gestational age. Decreased synthesis of IL-6, TNF- $\alpha$, IL-1 $\beta$, and granulo- 
cyte-colony stimulating factor (G-CSF), and increased concentrations of IL-10 have recently been measured ex vivo (26-28). In our experiments in very early preterm infants (gestational age $\leq 30 \mathrm{wk}$ ), the levels of TNF- $\alpha$, IL- $1 \beta$, and IL- 6 were significantly diminished in comparison to newborns from later gestational age $(>30 \mathrm{wk})$. In both groups of newborn infants, the ex vivo production of all three cytokines was markedly decreased in comparison to the adult group.

To our knowledge, the present study demonstrates for the first time that TLR4 expression in humans is age-related and particularly dependent on gestational aging, and that decreased expression of TLR4 in preterm infants correlates with decreased functional outcome of TLR4 stimulation, i.e. in decreased cytokine secretion. From our data we postulate that the immaturity of TLR4 contributes to the clinically relevant finding of immunologic vulnerability in the preterm infant. Impaired recognition of PAMP and reduced capability of cytokine production might contribute to the susceptibility of preterm infants to infections. Therapeutic interventions inducing the expression of TLR might be able to counter-regulate this vulnerable phase of the immune system.

\section{REFERENCES}

1. Kaftan H, Kinney JS 1998 Early onset neonatal bacterial infections. Semin Perinatol $22: 15-24$

2. Lott JW 2003 Neonatal bacterial sepsis. Crit Care Nurs Clin North Am 15:35-46

3. Lewis DB, Wilson CB 1995 Developmental immunology and role of host defences in neonatal susceptibility to infection. In: Remington JS, Klein JO (eds) Infectious Diseases of the Fetus and Newborn Infant. Saunders, Philadelphia, pp 20-99

4. Cairo MS 1989 Neonatal neutrophil host defence. Prospects for immunologic enhancement during neonatal sepsis. Am J Dis Child 143:40-56

5. Chalmers IM, Janossy G, Contreras M, Navarrete C 1998 Intracellular cytokine profile of cord and adult blood lymphocytes. Blood 92:11-18

6. Hallwirth U, Pomberger G, Zaknun D, Szepfalusi Z, Horcher E, Pollak A, Roth E, Spittler A 2002 Monocyte phagocytosis as a reliable parameter for predicting early-onset sepsis in very low birth weight infants. Early Hum Dev 67:1-9

7. Anderson KV, Bokla L, Nusslein-Volhard C 1984 Establishment of dorsal-ventral pattern of the Drosophila embryo is stored as maternal mRNA. Nature 311:223-227

8. Akira S 2001 Toll-like receptor and innate immunity. Adv Immunol 78:1-56

9. Beutler B 2002 Toll-like receptors: how they work and what they do. Curr Opin Hematol 9:2-10
10. Medzhitov R 2001 Toll-like receptors and innate immunity. Nat Rev Immunol $1: 135-145$

11. Underhill DM, Ozinsky A 2002 Toll-like receptors: key mediators of microbe detection. Curr Opin Immunol 14:103-110

12. Harju K, Glumoff V, Hallman M 2001 Ontogeny of Toll-like receptors Tlr2 and Tlr4 in mice. Pediatr Res 49:81-83

13. Spittler A, Reissner CM, Oehler R, Gornikiewicz A, Gruenberger T, Manhart N, Brodowicz T, Mittlboeck M, Boltz-Nitulescu G, Roth E 1999 Immunomodulatory effects of glycine on LPS-treated monocytes: reduced TNF-alpha production and accelerated IL-10 expression. FASEB J 13:563-571

14. Edwards WH 2002 Preventing nosocomial bloodstream infection in very low birth weight infants. Semin Neonatol 7:325-333

15. Auriti C, Maccallini A, Di Liso G, Di Ciommo V, Ronchetti MP, Orzalesi M 2003 Risk factors for nosocomial infections in a neonatal intensive-care unit. J Hosp Infect 53:25-30

16. Kilbride HW, Powers R, Wirtschafter DD, Sheehan MB, Charsha DS, LaCorte M, Finer N, Goldmann DA 2003 Evaluation and development of potentially better practices to prevent neonatal nosocomial bacteremia. Pediatrics 111:504-518

17. Spittler A, Razenberger M, Kupper H, Kaul M, Hackl W, Boltz-Nitulescu G, Függer R, Roth E 2000 Relationship between IL-6 plasma concentration in patients with sepsis, monocyte phenotype, monocyte phagocytic properties, and cytokine production. Clin Infect Dis 31:1338-1342

18. Medzhitov R, Janeway CA Jr 1997 Innate immunity: impact on the adaptive immune response. Curr Opin Immunol 9:4-9

19. Gengenbacher D, Salm H, Vogt A, Schneider H 1998 Detection of cell surface determinants for anti-Leu M3 (CD14), MY9 (CD33) and MY4 (CD14) and phagocytic function of cord blood monocytes in the course of gestational age. Bone Marrow Transplant 22:S48-S51

20. Hallwirth U, Pomberger G, Pollak A, Roth E, Spittler A 2004 Monocyte switch in neonates: high phagocytic capacity and low HLA-DR expression in VLBWI are inverted during gestational aging. Pediatr Allergy Immunol 15:513-516

21. Mills EL 1983 Mononuclear phagocytes in the newborn: their relation to the state of relative immunodeficiency. Am J Pediatr Hematol Oncol 5:189-198

22. Poltorak A, Smirnova I, Liu MY, Van Huffel C, Du X, Birdwell D, Alejos E, Silva M, Galanos C, Freudenberg M, Ricciardi-Castagnoli P, Layton B, Beutler B 1998 Defective LPS signalling in $\mathrm{C} 3 \mathrm{H} / \mathrm{HeJ}$ and $\mathrm{C} 57 \mathrm{BL} / 10 \mathrm{ScCr}$ mice: mutations in Tlr4 gene. Science 282:2085-2088

23. Agnese DM, Calvano JE, Hahm SJ, Coyle SM, Corbett SA, Calvano SE, Lowry SF 2002 Human toll-like receptor 4 mutations but not CD14 polymorphisms are associated with an increased risk of Gram-negative infections. J Infect Dis 186:1522-1525

24. Feterowski C, Emmanuilidis K, Miethke T, Gerauer K, Rump M, Ulm K, Holzmann B, Weighardt H 2003 Effects of functional Toll-like receptor-4 mutations on the immune response to human and experimental sepsis. Immunology 109:426-431

25. Heine H, Lien E 2003 Toll-like receptors and their function in innate and adaptive immunity. Int Arch Allergy Immunol 130:180-192

26. Weimann E, Rutkowski S, Reisbach G 1998 G-CSF, GM-CSF and IL-6 levels in cord blood: diminished increase of G-CSF and IL-6 in pre-terms with perinatal infection compared to term neonates. J Perinat Med 26:211-218

27. Blanco-Quiros A, Arranz E, Solis G, Villar A, Ramos A, Coto D 2000 Cord blood interleukin-10 levels are increased in pre-term newborns. Eur J Pediatr 159:420-423

28. Dembinski J, Behrendt D, Martini R, Heep A, Bartmann P 2003 Modulation of proand anti-inflammatory cytokine production in very pre-term infants. Cytokine 21:200-206 